\title{
Limited effects on patient outcomes of conjoint tendon release in anterolateral muscle-sparing total hip arthroplasty
}

Hidetatsu Tanaka ${ }^{1 *}$, Norikazu Yamada ${ }^{1}$, Hiroaki Kurishima² ${ }^{2}$ Yu Mori ${ }^{2}$, Takashi Sakamoto ${ }^{1}$, Masamizu Oyama ${ }^{1}$ and Toshimi Aizawa ${ }^{2}$

\begin{abstract}
Background: The anterolateral muscle-sparing total hip arthroplasty (THA) in the supine position is advantageous owing to the very low-dislocation rate and excellent leg length discrepancy control. However, femur exposure is challenging. Although the conjoined external rotators tendon (CERT) release is effective in improving femoral access, the effects on clinical outcomes remain unclear. The purpose of this study was to evaluate the clinical and radiographic results of CERT release in the anterolateral muscle-sparing THA approach.

Methods: The study was performed as a retrospective cohort study and included 85 hips in 85 patients who underwent primary anterolateral THA. Clinical and radiographic outcomes were investigated 6 months and 1 year after THA (CERTpreserved and non-released patients). The Japanese Orthopaedic Association (JOA) hip score, JOA Hip-disease Evaluation Questionnaire (JHEQ), forgotten joint score (FJS), and the 36 short-form questionnaires (SF-36 mental and physical) were evaluated. The leg length discrepancy, cup inclination and stem orientation were evaluated with radiographs.

Results: Among all the included hips, 37 patients (43.5\%) retained the CERT, and 48 patients (56.5\%) included the released CERT. There were no significant differences in the JOA hip scores, JHEQ, FJF-12 and SF-36 between the released and non-released groups. There were significant differences in sagittal stem alignments between groups.

Conclusion: The CERT release in anterolateral muscle-sparing THA has a limited effect on post-operative clinical outcomes. The CERT release improved the femur exposure and is more invasive than the preserved CERT. We infer that the CERT should be maintained in patients with a wide range of motions, and release the CERT in inadequate femur canal preparation cases.
\end{abstract}

Keywords: Total hip arthroplasty, conjoined external rotators tendon, patient outcome

\section{Introduction}

Total hip arthroplasty (THA) provides pain relief and restoration of functionality in osteoarthritic hips and leads to the improvement of the patients' quality of life [1]. Recent studies have demonstrated that THA with the minimally invasive techniques is effective in reducing

\footnotetext{
* Correspondence: hidetatsu.tanaka@med.tohoku.ac.jp

'Department of Orthopaedic Surgery, Japanse Redcross Sendai Hospital, 43-3, 2 cho-me, yagiyama hon-cho, taihaku-ku, Sendai 982-8501, Japan

Full list of author information is available at the end of the article
}

soft tissue damage, peri-operative pain, blood loss, and achieves faster recovery times and shorter hospitalization periods [2-5]. The anterior-based muscle-sparing (ABMS) THA is less popular than the direct anterior approach (DAA) applied to the hip, clinically effective, safe, very low-dislocation rate and, the excellent control of the leg length discrepancy [6]. Minimally invasive total hip replacement via the anterolateral approach in the supine position has yielded excellent clinical results [6, 7].

(c) The Author(s). 2021 Open Access This article is licensed under a Creative Commons Attribution 4.0 International License, which permits use, sharing, adaptation, distribution and reproduction in any medium or format, as long as you give appropriate credit to the original author(s) and the source, provide a link to the Creative Commons licence, and indicate if changes were made. The images or other third party material in this article are included in the article's Creative Commons licence, unless indicated otherwise in a credit line to the material. If material is not included in the article's Creative Commons licence and your intended use is not permitted by statutory regulation or exceeds the permitted use, you will need to obtain permission directly from the copyright holder. To view a copy of this licence, visit http://creativecommons.org/licenses/by/4.0/ The Creative Commons Public Domain Dedication waiver (http://creativecommons.org/publicdomain/zero/1.0/) applies to the data made available in this article, unless otherwise stated in a credit line to the data. 
The conjoined external rotators tendon (CERT; conjoined tendons of the gemellus superior, obturator internus and, gemellus inferior) have been proposed as the key active stabilizers of the hip, along with the internally rotating gluteus minimus, are often described as the "rotator cuff" of the hip [8]. The CERT can help the external rotation of the hip and the stabilization of the hip joint [9] and is important to prevent posterior dislocation of the hip after THA $[10,11]$. Although the anterior or anterolateral minimally invasive technique is reported as muscle-sparing THA, the surgeons sometimes need additional soft tissue release for canal preparation of the femur, such as the capsular ligament or the insertion of muscles around the hip including the CERT. These releases enable good canal preparation, insertion of broaches, and trials.

Currently, the clinical effects of CERT release in DAA THA are being investigated, only a few studies have described the effects of CERT release in DAA THA [12]. Consequently, the effects of CERT release in ABMS THA remain unresolved. The purpose of this study was to evaluate the clinical and radiographic results of CERT release in the anterolateral muscle-sparing THA approach.

\section{Materials and Methods}

This was a single-center, retrospective data collection study, approved by our hospital's institutional review board. The study considered for inclusion 92 hips from 92 patients who underwent unilateral primary THA with ABMS in the supine position at our institution between July 2017 and August 2018. The indication of THA with ABMS in this study was 1) no history of previous surgery on the affected hip, 2) primary osteoarthritis of the hip and osteonecrosis, and 3) secondary osteoarthritis of the hip with Crowe classification from 1 to 3 . All hips were examined clinically and radiographically at 6 months and 1 year after surgery. Of these, three hips with opposite THA, two hips with total knee arthroplasty, and one hip with the tibial fracture within 12 months, and one hip with the onset of cerebral infarction on the perioperative period were excluded from the analysis. Finally, in total, 85 hips from 85 patients were included in this study. The baseline demographic data are listed in Table 1, including the age, gender, body mass index (BMI), follow-up periods, and diagnosis.

\section{Surgical technique}

All surgeries were performed via the anterolateral muscle-sparing approach in the supine position (ABMSTHA) [6]. Both legs were draped, and the length of the skin incision ranged between 7 and $10 \mathrm{~cm}$. The muscular plane between the gluteus medius and tensor fascia latae was developed. The anterior capsule was incised,
Table 1 Patient demographic data

\begin{tabular}{ll}
\hline Number of patients & 85 \\
Age at the operation, mean \pm SD (range) & $66.4 \pm 8.1(46-87)$ \\
Gender Female:Male, no. of patients (\%) & $77(90.6): 8(9.4)$ \\
BMI & $24.7 \pm 3.2(15.9-34.2)$ \\
follow-up period, mean \pm SD (months) (range) & $34.5 \pm 3.7(28-42)$ \\
Diagnosis, Stage (no. of hips) & \\
Osteoarthritis of the hip & 84 \\
Traumatic osteonecrosis & 1 \\
\hline
\end{tabular}

Data represent mean \pm standard deviation

including a vertical band of the iliofemoral ligament that was left about $10 \mathrm{~mm}$ from the medial border of the anterior capsule. The femoral neck was cut without a hip dislocation, and the femoral head was removed. The cup was inserted at a $40^{\circ}$ inclination based on the interconnection line of the bilateral anterior-superior iliac spine and alignment rod for the inclination of cup positioner, and at an anteversion angle of $15^{\circ}$ with reference to the operation table and cup positioner.

The preparation for stem insertion was performed. The capsular which remained, including a horizontal band of the iliofemoral ligament at the anterior part of the medial surface of the greater trochanter, was carefully resected. The CERT was confirmed and was retained as much as possible to provide stability. Regarding the CERT release, it was determined by the difficulty associated with the exposure of the canal of the femur during surgery. The CERT was released at the attachment site from the anterior to the posterior direction to achieve alignment [13]. If an additional elevation or lateralization of the femur was required, the external obturator muscle and posterior capsule attachments to the posterior part of the femoral neck were released as needed.

The head size, length, and offset were determined based on pre-operative templating, and minor adjustments were made intraoperatively. On the acetabular side, G7 cup and E1 acetabular flat liner (Zimmer Biomet, Warsaw, IN, USA) were used. On the femoral side the implant choice was made depending on the femoral shape or anteversion, Taperloc/Microplasty in 78 hips, Wagner cone in four hips, CL Spotorno in two hips (Zimmer Biomet, Warsaw, IN, USA), and C-stem AMT in one hip (DePuy Synthes, Warsaw, IN, USA). In the post-operative rehabilitation, patients were allowed immediate full-weight-bearing with a walker or crutches.

\section{Evaluation}

Evaluation of the health status included the assessment of BMI. The duration of surgery, amount of blood loss during the operation, and post-operative complications were recorded. 
Clinical assessments were performed using the Japanese Orthopaedic Association (JOA) hip scores [14] as the clinician-reported outcome measures (CROMs) preoperatively, and at 6 and 12 months post-operatively. Additionally, patient-reported outcome measures (PROMs) were evaluated with the Japanese Orthopaedic Association Hip-disease Evaluation Questionnaire (JHEQ) [15, 16] and Forgotten Joint Score (FJS) [17]. The JHEQ consisted of pain, movement, and mental subscales, which were assessed pre-operatively, at 6 and 12 months post-operatively. The FJS was useful in Japan [18], and evaluated at 6 and 12 months post-operatively. The individual patient health status was monitored based on the short-form 36 questionnaires (SF-36 mental and physical) which included physical (Physical component summary: PCS) and mental sections (Mental component summary: MCS) pre-operatively and at 12 months postoperatively [19-21]. The questionnaires were completed by the patients themselves.

Conventional anteroposterior radiographs of the pelvis, including both hips and cross-table lateral views of the hip, were obtained to check the implant fixation. The pre-operative and post-operative leg length discrepancy (absolute value), cup inclination, stem orientation (valgus or varus angles), and subsidence of stem were assessed with anteroposterior radiographs. The cup anteversion and stem sagittal alignment (flexion or extension angles) were evaluated based on lateral views.

\section{Statistical analysis}

Statistical analyses were performed using the EZR (Saitama Medical Centre, Jichi Medical University, Saitama, Japan), which is a graphical user interface for $\mathrm{R}$ (The $\mathrm{R}$ Foundation for Statistical Computing, Vienna, Austria) [22]. Specifically, it is a modified version of the $\mathrm{R}$ commander designed to add statistical functions and is frequently used in biostatistics. Wilcoxon signed-rank tests were used to compare the pre-operative and post-operative clinical and radiographic scores. The comparisons of continuous variables were compared with the Mann-Whitney U test. Fisher's exact tests were used to compare

Table 2 JOA and JHEQ scores preoperatively, and at 6 and 12 months postoperatively

\begin{tabular}{|c|c|c|c|}
\hline & Non Released & Released & $p$ value \\
\hline Number & 37 & 48 & \\
\hline Age & $66.2 \pm 7.9$ & $67.4 \pm 8.7$ & 0.35 \\
\hline BMl & $24.5 \pm 3.2$ & $24.8 \pm 3.5$ & 0.59 \\
\hline Duration of surgery & $80.7 \pm 16.1$ & $93.0 \pm 23.0$ & $0.00^{*}$ \\
\hline Amount of blood loss & $304.8 \pm 150.4$ & $369.8 \pm 144.4$ & $0.01^{*}$ \\
\hline \multicolumn{4}{|l|}{ Osteoarthritis grade } \\
\hline Tonnis grade 1 & 4 & 3 & 0.75 \\
\hline Tonnis grade 2 & 4 & 6 & \\
\hline Tonnis grade 3 & 29 & 39 & \\
\hline \multicolumn{4}{|l|}{ The number of additional release } \\
\hline the external obturator muscle attachment & 0 & 3 & \\
\hline posterior capsule attachment to the posterior & 0 & 5 & \\
\hline \multicolumn{4}{|l|}{ Stem selection } \\
\hline Taperloc/ Microplasty & 36 & 42 & \\
\hline Wagner cone & 0 & 4 & \\
\hline CL Spotorno & 0 & 2 & \\
\hline C-stem AMT & 1 & 0 & \\
\hline \multicolumn{4}{|l|}{ Complication } \\
\hline dislocation & 0 & 0 & \\
\hline infection & 0 & 0 & \\
\hline great trochanter fracture & 1 & 1 & \\
\hline subsidence of stem, more than $3 \mathrm{~mm}$ & 2 & 1 & \\
\hline
\end{tabular}

Data represent mean \pm standard deviation

${ }^{*} \mathrm{P}<0.05$

Mann Whitney $\mathrm{U}$ test was performed to compare scores between the groups

Fisher's exact test to compare numbers in OA grade and stem selection between the groups 
demographic data between the groups. The level of significance was set at $\mathrm{p}=0.05$.

\section{Results}

Among all the included hips, 37 hips (43.5\%) retained a CERT (Non-released group) and 48 hips (56.5\%) included a CERT release (Released group). The mean ages and BMI were not significantly different (Table 2). The duration of surgery was significantly longer and the amount of blood loss was more extensive in the released group (Table 2). The four hips needed an additional release of the external obturator muscle attachment.

The JOA hip score, all JHEQ scores, and PCS score of the SF-36 were significantly improved without the MCS score (Table 3). There were no significant differences in the JOA hip score, JHEQ, FJF-12, and SF-36 between the non-released group and released groups (Tables 4, 5).

There were significant differences in the stem flexion angle between the groups. The pre-operative and postoperative leg length discrepancies, extension lengths, cup inclinations, anteversions, and stem varus angles were not significant (Table 6).

\section{Discussion}

The clinical results of this study had excellent postoperative outcomes for THA, given that the hip clinical scores were significantly improved (with the exception of the mental section of SF-36), regardless of the CERT release. Furthermore, the leg length discrepancy was improved. The ABMS for THA with preserved CERT was less invasive, the duration of surgery was significantly longer, and the amount of blood loss was more extensive in the released group.

Although the deep external rotators have been proposed as key active stabilizers of the hip described as the 'rotator cuff' of the hip [8], the CERT release during the DAA in THA has no impact on gait or patient-reported outcomes within the 12-week period post-surgery [23]. Yao et al. investigated the outcome of DAA for THA and showed that the CERT release was not predictive of the length of stay, one year inpatient pain medication requirements, or outcome scores [12]. These results were consistent with the results of the present study, wherein $56.5 \%$ of the hips included a conjoint tendon release irrespective of whether the CERT released or not in anterolateral muscle-sparing THA, and had limited effects on patient outcomes at six months and one-year based on the use of CROMs and PROMs. Specifically, FJS was considered as the most sensitive score and the ultimate goal in joint arthroplasty [17] and tended to show greater dispersion and more marked differences between patients [18].

The importance of preservation of CERT for postoperative hip stability has been described in the case of the posterior approach [24], to prevent posterior dislocation of the hip after THA [10, 11]. The data of the present study showed no dislocation, irrespective of whether the attachment of CERT (released or not) affected the post-operative stability in ABMS for THA. Conversely, if the CERT was released in the non-released group cases, joint instability may be increased.

A cadaveric study has shown considerable variation in the attachments of CERT [13]. The CERT insertion is mostly attached to the anterior part of the femur among the short external rotation muscles [25]. The damage of the obturator internal muscle depended upon the injury at CERT insertions [26] and induced a decrease of the muscle volume [9]. In the surgical steps of the present study, the CERT was released at the attachment site from the anterior to the posterior directions in the case of inadequate canal preparations. The CERT was related to the adjustment of the range of motion and the joint stability, the present study showed the limited effect on

Table 3 JOA, JHEQ and Summary scores of SF-36 before operation, and at 6 and 12 months postoperatively

\begin{tabular}{|c|c|c|c|c|c|}
\hline & pre operation & at 6 months & $p$ value & at 12 months & p value \\
\hline JOA score & $44.8 \pm 12.7$ & $95.2 \pm 5.8$ & $0.000^{*}$ & $95.7 \pm 7.4$ & $0.00^{*}$ \\
\hline \multicolumn{6}{|l|}{ JHEQ score } \\
\hline total (84) & $20.7 \pm 10.3$ & $65.8 \pm 12.0$ & $0.000^{*}$ & $70.2 \pm 10.7$ & $0.00^{*}$ \\
\hline pain (28) & $6.4 \pm 4.0$ & $25.4 \pm 3.5$ & $0.000^{*}$ & $26.0 \pm 2.8$ & $0.00^{*}$ \\
\hline movement (28) & $4.0 \pm 3.5$ & $18.7 \pm 6.0$ & $0.000^{*}$ & $20.8 \pm 5.7$ & $0.00^{*}$ \\
\hline mental (28) & $10.4 \pm 5.6$ & $22.2 \pm 5.5$ & $0.000^{*}$ & $23.8 \pm 4.5$ & $0.00^{*}$ \\
\hline dissatisfaction scale (100) & $87.3 \pm 11.8$ & $8.7 \pm 12.1$ & $0.000^{*}$ & $8.9 \pm 14.8$ & $0.00^{*}$ \\
\hline SF-36 PCS & $22.3 \pm 10.0$ & $39.3 \pm 11.7$ & $0.000^{*}$ & $41.7 \pm 11.3$ & $0.00^{*}$ \\
\hline SF-36 MCS & $56.0 \pm 9.3$ & $57.9 \pm 8.1$ & 0.094 & $56.8 \pm 9.2$ & 0.74 \\
\hline
\end{tabular}

Data represent mean \pm standard deviation

${ }^{*} \mathrm{P}<0.05$

Willcoxon single rank test was performed to compare scores

between pre operration and 6 and 12 months after surgery 
Table 4 JOA and JHEQ scores between two groups

\begin{tabular}{|c|c|c|c|}
\hline & Non Released & Released & $p$ value \\
\hline \multicolumn{4}{|c|}{ JOA score } \\
\hline pre operation & $44.3 \pm 14.3$ & $45.2 \pm 11.4$ & 0.6 \\
\hline at 6 months & $96.0 \pm 5.6$ & $94.6 \pm 6.0$ & 0.32 \\
\hline at 12 months & $94.9 \pm 9.7$ & $96.3 \pm 4.9$ & 0.74 \\
\hline \multicolumn{4}{|l|}{ JHEQ score } \\
\hline \multicolumn{4}{|l|}{ pre operation } \\
\hline total (84) & $21.2 \pm 10.1$ & $20.3 \pm 10.6$ & 0.8 \\
\hline pain (28) & $6.5 \pm 4.4$ & $6.3 \pm 3.8$ & 0.97 \\
\hline movement (28) & $3.7 \pm 3.3$ & $4.2 \pm 3.6$ & 0.53 \\
\hline mental (28) & $11.0 \pm 5.3$ & $9.9 \pm 5.9$ & 0.51 \\
\hline dissatisfaction scale (100) at 6 months & $86.1 \pm 12.3$ & $88.2 \pm 11.4$ & 0.35 \\
\hline total (84) & $68.8 \pm 11.8$ & $64.9 \pm 11.8$ & 0.12 \\
\hline pain (28) & $25.9 \pm 3.7$ & $25.0 \pm 3.4$ & 0.23 \\
\hline movement (28) & $19.9 \pm 6.0$ & $17.9 \pm 5.9$ & 0.1 \\
\hline mental (28) & $23.2 \pm 5.5$ & $22.8 \pm 5.5$ & 0.42 \\
\hline dissatisfaction scale (100) at 12 months & $9.3 \pm 13.0$ & $8.52 \pm 11.6$ & 0.91 \\
\hline total (84) & $70.7 \pm 11.9$ & $69.8 \pm 9.7$ & 0.4 \\
\hline pain (28) & $26.5 \pm 2.6$ & $25.6 \pm 2.8$ & 0.12 \\
\hline movement (28) & $20.8 \pm 6.7$ & $20.9 \pm 4.9$ & 0.48 \\
\hline mental (28) & $23.8 \pm 4.7$ & $23.8 \pm 4.4$ & 0.72 \\
\hline dissatisfaction scale (100) & $7.4 \pm 15.3$ & $10.1 \pm 14.4$ & 0.14 \\
\hline
\end{tabular}

Data represent mean \pm standard deviation

${ }^{*} \mathrm{P}<0.05$

Mann Whitney $\mathrm{U}$ test was performed to compare scores between groups

patient-reported outcomes, including pain and daily-life activities.

The radiographic evaluation showed that stem sagittal alignment was more flexion in the nonreleased group, while no significant differences

Table 5 Forgotten joint score and Summary score of SF-36 between two groups

\begin{tabular}{llll}
\hline & Non Released & Released & p value \\
\hline $\begin{array}{l}\text { Forgotten joint score } \\
\text { at } 6 \text { months }\end{array}$ & $66.9 \pm 18.5$ & $58.5 \pm 19.8$ & 0.06 \\
at 12 months & $74.1 \pm 15.2$ & $72.5 \pm 13.8$ & 0.64 \\
SF-36 PCS & & & \\
pre operation & $22.7 \pm 11.5$ & $22.1 \pm 8.7$ & 0.83 \\
6 months & $39.4 \pm 12.4$ & $39.2 \pm 11.3$ & 0.94 \\
12 months & $42.7 \pm 11.2$ & $41.0 \pm 11.5$ & 0.56 \\
SF-36 MCS & & & \\
pre operation & $55.7 \pm 8.2$ & $56.2 \pm 10.1$ & 0.86 \\
6 months & $58.6 \pm 8.0$ & $57.4 \pm 8.2$ & 0.31 \\
12 months & $56.5 \pm 9.6$ & $57.0 \pm 9.0$ & 0.87 \\
\hline
\end{tabular}

Data represent mean \pm standard deviation

${ }^{*} \mathrm{P}<0.05$

Mann Whitney $\mathrm{U}$ test was performed to compare scores between groups existed in the stem valgus/varus alignment. The stem tended to be inserted from the anterior part of the osteotomy site of the femur if the canal preparation was inadequate. Yoshitani et al. reported that there were no significant differences in clinical or radiographic outcomes between flexion and neutral alignment of the tapered-wedge stem at an average follow-up period of 4.7 years [27]. The difference in the sagittal alignment of our data had a limited effect on the clinical course.

Our study has certain limitations. The first limitation is that this study was a nonrandomized control study. The CERT release depended on the cases, and hips with contracture may have tended to release the capsular band and CERT. The second limitation was stem selection. The choice of the stem was according to the shape of the femur, anteversion, and offset; the differences in the shape of the stem shoulder or stem length affected the capsular band and CERT release, and femur canal preparation. The third limitation pertains to the fact that our study did not include shorter-term outcomes. We may detect short-term clinical differences if shorter-term outcomes were examined. 
Table 6 Radiographic parameters

\begin{tabular}{llll}
\hline & Non Released & Released & p value \\
\hline preoperative leg length discrepancy & $-7.9 \pm 8.9$ & $-9.9 \pm 9.5$ & 0.71 \\
postoperative leg length discrepancy & $0.2 \pm 6.8$ & $-0.9 \pm 9.0$ & 0.76 \\
Leg extension length & $7.2 \pm 6.2$ & $8.5 \pm 8.1$ & 0.36 \\
cup inclination & $42.5 \pm 5.5$ & $44.7 \pm 4.5$ & 0.06 \\
cup anteversion & $18.2 \pm 5.4$ & $20.0 \pm 6.0$ & 0.46 \\
stem varus angle & $1.9 \pm 5.4$ & $1.2 \pm 2.5$ & 0.78 \\
stem flexion angle & $7.2 \pm 3.5$ & $4.2 \pm 3.8$ & $0.04^{*}$ \\
\hline
\end{tabular}

Data represent mean \pm standard deviation

${ }^{*} \mathrm{P}<0.05$

Mann Whitney $\mathrm{U}$ test was performed to compare scores between groups

\section{Conclusions}

The CERT release in anterolateral muscle-sparing total hip arthroplasty has a limited effect on postoperative clinical outcomes. Although the CERT release improves femur exposure, the CERT has limited effects on patient outcomes at 6 months and one year post-surgery. The CERT release was more invasive than the preserved CERT, and the thresholds levels may be low. Surgeons should try to leave the CERT for patients with a wide range of motion as much as possible, and release the CERT for inadequate femur canal preparation.

\section{Abbreviations}

THA: total hip arthroplasty; ABMS: anterior-based muscle-sparing; DAA: direct anterior approach; CERT: conjoined external rotators tendon; BMI: body mass index; JOA: Japanese Orthopaedic Association; CROMs: clinician reported outcome measures; PROMs: patient-reported outcome measures; JHEQ: Japanese Orthopaedic Association Hip-disease Evaluation Questionnaire; FJF: forgotten joint score; SF-36: 36-Item. Short-Form Health Survey; PCS: Physical component summary; MCS: Mental component summary

\section{Acknowledgements}

Not applicable

\section{Authors' contributions}

Authors H.T., N.Y. and H.K. designed the study. Authors Y.M. and T. A. contributed to analysis and interpretation of data. Author H.T. collected the data and wrote the manuscript with support from T.S. and M.O. All authors discussed the results and contributed to the final manuscript. All authors approved the final version of the manuscript

\section{Funding}

The authors received no financial support for the research, authorship, and/ or publication of this article.

\section{Availability of data and materials}

The datasets used and/or analyzed during the current study are available from the corresponding author on reasonable request.

\section{Declarations}

\section{Ethics approval and consent to participate}

The study protocol was approved by the Ethics Committees of Japanese Redcross Hospital (Number 119-3).

\section{Consent for publication}

There is no patient identifiable information and data in this manuscript.

\section{Competing interests}

The authors declare that they have no competing interests.

\section{Author details}

${ }^{1}$ Department of Orthopaedic Surgery, Japanse Redcross Sendai Hospital, 43-3, 2 cho-me, yagiyama hon-cho, taihaku-ku, Sendai 982-8501, Japan.

${ }^{2}$ Department of Orthopaedic Surgery, Tohoku University Graduate School of Medicine, 1-1 Seiryo-machi, Aoba-ku, Sendai 980-8574, Japan.

Received: 24 June 2021 Accepted: 28 July 2021

Published online: 10 August 2021

\section{References}

1. Anseth SD, Pulido PA, Adelson WS, Patil S, Sandwell JC, Colwell CW Jr. Fifteen-year to twenty-year results of cementless Harris-Galante porous femoral and Harris-Galante porous I and II acetabular components. J Arthroplasty. 2010;25(5):687-91.

2. Capuano N, Grillo G, Carbone F, Del Buono A. Total hip arthroplasty performed with a tissue-preserving technique using superior capsulotomy Int Orthop. 2018:42(2):281-7.

3. Leunig M, Faas M, von Knoch F, Naal FD. Skin crease 'bikini' incision for anterior approach total hip arthroplasty: surgical technique and preliminary results. Clin Orthop Relat Res. 2013:471(7):2245-52.

4. Homma Y, Baba T, Kobayashi H, Desroches A, Ozaki Y, Ochi H, et al. Safety in early experience with a direct anterior approach using fluoroscopic guidance with manual leg control for primary total hip arthroplasty: a consecutive one hundred and twenty case series. Int Orthop. 2016;40(12): 2487-94.

5. George NE, Gwam CU, Etcheson Jl, Smith SS, Semenistyy AA, Delanois RE Short-term outcomes of the supine muscle-sparing anterolateral versus direct lateral approach to primary total hip arthroplasty. Hip Int. 2019;29(5): $504-10$

6. Civinini R, Cozzi Lepri A, Carulli C, Matassi F, Villano M, Innocenti M. The anterior-based muscle-sparing approach to the hip: the "other" anterior approach to the hip. Int Orthop. 2019;43(1):47-53.

7. Pfluger $G$, Junk-Jantsch S, Scholl V. Minimally invasive total hip replacement via the anterolateral approach in the supine position. Int Orthop. 2007; 31(Suppl 1):S7-11.

8. KMC THR, Grimaldi A, Kemp JL, Cowan SM. Can local muscles augment stability in the hip? A narrative literature review. J Musculoskelet Neuronal Interact. 2013;13(1):1-12.

9. Xu D, Koyama H, Furuhashi H, Nishikino S, Hoshino H, Matsuyama Y. Comparison of hip muscle volume between fit-and-fill stem and taperedwedge stem after total hip arthroplasty using the anterolateral approach. J Orthop Sci. 2017;22(6):1102-6.

10. Iorio R, Specht LM, Healy WL, Tilzey JF, Presutti AH. The effect of EPSTR and minimal incision surgery on dislocation after THA. Clin Orthop Relat Res. 2006:447:39-42.

11. Goldstein WM, Gleason TF, Kopplin M, Branson JJ. Prevalence of dislocation after total hip arthroplasty through a posterolateral approach with partial capsulotomy and capsulorrhaphy. J Bone Joint Surg Am. 2001;83-A Suppl 2(Pt 1):2-7. 
12. Yao R, Howard JL, Lanting BA. Conjoint Tendon Release in Direct Anterior Total Hip Arthroplasty: No Impact on Patient Outcomes. Orthopedics. 2017; 40(6):e971-e4.

13. Ito $Y$, Matsushita I, Watanabe H, Kimura T. Anatomic mapping of short external rotators shows the limit of their preservation during total hip arthroplasty. Clin Orthop Relat Res. 2012;470(6):1690-5.

14. Takeda H, Kamogawa J, Sakayama K, Kamada K, Tanaka S, Yamamoto H. Evaluation of clinical prognosis and activities of daily living using functional independence measure in patients with hip fractures. J Orthop Sci. 2006; 11(6):584-91.

15. Matsumoto T, Kaneuji A, Hiejima Y, Sugiyama H, Akiyama H, Atsumi T, et al. Japanese Orthopaedic Association Hip Disease Evaluation Questionnaire (JHEQ): a patient-based evaluation tool for hip-joint disease. The Subcommittee on Hip Disease Evaluation of the Clinical Outcome Committee of the Japanese Orthopaedic Association. J Orthop Sci. 2012 17(1):25-38

16. Fukui K, Kaneuji A, Sugimori T, Ichiseki T, Matsumoto T, Hiejima Y. Clinical assessment after total hip arthroplasty using the Japanese Orthopaedic Association Hip-Disease Evaluation Questionnaire. J Orthop. 2015;12(Suppl 1):S31-6.

17. Behrend $\mathrm{H}$, Giesinger $\mathrm{K}$, Giesinger JM, Kuster MS. The "forgotten joint" as the ultimate goal in joint arthroplasty: validation of a new patient-reported outcome measure. J Arthroplasty. 2012;27(3):430-6 e1.

18. Matsumoto M, Baba T, Homma Y, Kobayashi H, Ochi H, Yuasa T, et al. Validation study of the Forgotten Joint Score-12 as a universal patient-reported outcome measure. Eur J Orthop Surg Traumatol. 2015;25(7):1141-5.

19. Garratt A, Schmidt L, Mackintosh A, Fitzpatrick R. Quality of life measurement: bibliographic study of patient assessed health outcome measures. BMJ. 2002;324(7351):1417.

20. Fukuhara S, Bito S, Green J, Hsiao A, Kurokawa K. Translation, adaptation, and validation of the SF-36 Health Survey for use in Japan. J Clin Epidemiol. 1998;51:1037-44

21. Fukuhara S, Ware JE, Kosinski M, Wada S, Gandek B. Psychometric and clinical tests of validity of the Japanese SF-36 Health Survey. J Clin Epidemiol. 1998:51:1045-53.

22. Kanda Y. Investigation of the freely available easy-to-use software 'EZR' for medical statistics. Bone Marrow Transplant. 2013;48(3):452-8.

23. Zomar BO, Bryant D, Hunter S, Howard JL, Lanting BA. The effect of conjoint tendon release on gait after direct anterior total hip arthroplasty. Hip Int 2019;29(6):578-83.

24. White RE Jr, Forness TJ, Allman JK, Junick DW. Effect of posterior capsular repair on early dislocation in primary total hip replacement. Clin Orthop Relat Res. 2001;393:163-7.

25. Walters BL, Cooper JH, Rodriguez JA. New findings in hip capsular anatomy: dimensions of capsular thickness and pericapsular contributions. Arthroscopy. 2014;30(10):1235-45.

26. Meneghini RM, Pagnano MW, Trousdale RT, Hozack WJ. Muscle damage during MIS total hip arthroplasty: Smith-Petersen versus posterior approach. Clin Orthop Relat Res. 2006;453:293-8.

27. Yoshitani J, Kabata T, Kajino Y, Takagi T, Ohmori T, Ueno T, et al. The effect of flexion alignment in total hip arthroplasty with a cementless taperedwedge femoral stem. Eur J Orthop Surg Traumatol. 2018;28(8):1625-32.

\section{Publisher's Note}

Springer Nature remains neutral with regard to jurisdictional claims in published maps and institutional affiliations.

Ready to submit your research? Choose BMC and benefit from:

- fast, convenient online submission

- thorough peer review by experienced researchers in your field

- rapid publication on acceptance

- support for research data, including large and complex data types

- gold Open Access which fosters wider collaboration and increased citations

- maximum visibility for your research: over $100 \mathrm{M}$ website views per year

At BMC, research is always in progress.

Learn more biomedcentral.com/submissions 